\title{
Molecular studies in Finnish patients with familial juvenile nephronophthisis exclude a founder effect and support a common mutation causing mechanism
}

\author{
S Ala-Mello, E-M Sankila, O Koskimies, A de la Chapelle, H Kääriäinen
}

\begin{abstract}
Familial juvenile nephronophthisis (NPH) is an autosomal recessive tubulointerstitial kidney disease associated with formation of medullary and corticomedullary cysts. It progresses to end stage renal failure and its biochemical defect is unknown. An NPH locus has been assigned to a $2 \mathrm{cM}$ interval on chromosome 2 q13 by linkage studies. Homozygous deletions of approximately $250 \mathrm{~kb}$ have been detected in $80 \%$ of familial cases and $65 \%$ of sporadic cases and a common mutation mechanism has been suggested. We examined 14 Finnish families for the presence or absence of a deletion. After detecting a deletion in 12 patients belonging to nine families, we studied a possible founder effect by haplotype analysis using markers D2S340, D2S1889, and D2S1893. No common ancestral disease associated haplotype was found suggesting no founder effect. Results of pairwise linkage analyses were suggestive of linkage in the nine families with a deletion (lod scores of 1.39-3.89 at a recombination fraction of 0 ). Negative lod scores were obtained in the five families without a deletion suggesting that the disease locus in these families lies elsewhere. The end stage renal disease occurred at a more advanced age in patients without a deletion compared to patients with a deletion, indicating a phenotypic difference between these two groups.

$(\Im$ Med Genet 1998;35:279-283)
\end{abstract}

Keywords: familial juvenile nephronophthisis; 2q13 deletion; haplotype analysis

Familial juvenile nephronophthisis (NPH) is an autosomal recessive kidney disease that leads progressively to end stage renal failure. ${ }^{1}$ Medullary cystic disease $(\mathrm{MCD})^{2}$ was previously considered as a separate entity but as it has clinical symptoms similar to NPH it has subsequently been considered to be the same disease. $^{34}$ The term nephronophthisismedullary cystic disease complex refers to this entity.

The main clinical features of NPH are polydipsia and polyuria caused by decreasing urine concentrating capacity, growth retardation, and anaemia. ${ }^{125}$ Renal histology shows characteristic but non-specific features which resem- ble those of chronic tubulointerstitial nephritis. Macroscopic cysts are seen in the medulla and at the corticomedullary junction. ${ }^{6}$ Light microscopy shows that the tubular basement membranes are extremely thickened and layered and the tubules either dilated or hypertrophied and collapsed. The pathogenesis of NPH is unknown and most research has been aimed at the study of the components of the tubular basement membrane. ${ }^{7}$

Usually NPH affects the kidneys only, but syndromic forms also exist. These show extrarenal manifestations like retinitis pigmentosa in the Senior-Loken syndrome,,${ }^{10}$ liver fibrosis, ${ }^{11}$ cone shaped epiphyses, and cerebellar dysfunction ${ }^{12}$ in association with kidney disease which is identical to NPH. The delineation of $\mathrm{NPH}$ and its syndromic forms as well as the terminology is still controversial.

An NPH locus has been assigned by linkage studies to chromosome $2 \mathrm{q} 13 .{ }^{13-16}$ The locus has been further refined to a $2 \mathrm{cM}$ region between markers D2S1890 and D2S1888. ${ }^{17}$ When testing both familial and sporadic patients with non-polymorphic markers mapping to this region, large scale rearrangements, which turned out to be homozygous deletions of approximately $250 \mathrm{~kb}$ involving a $100 \mathrm{~kb}$ inverted duplication and two non-polymorphic markers $765 \mathrm{~F} 2 \mathrm{~L}$ and $804 / 6$, were seen in the majority of the patients. In one patient, a larger deletion comprising marker $804 \mathrm{H} 10 \mathrm{R}$ in addition to the two other markers was seen. This most probably indicates a recurrent deletion mechanism causing NPH, although a founder effect has also been suggested. ${ }^{17}$ Genetic heterogeneity has been shown, as linkage to 2 q13 was excluded in some families with NPH without extrarenal manifestations. ${ }^{15}$ Of the syndromic forms, at least the Senior-Loken syndrome has been excluded from $2 \mathrm{q} 13 .^{13}$

The purpose of this study was to evaluate the role of the chromosome $2 \mathrm{q} 13$ locus in the aetiology of NPH in Finland. More specifically, the study was undertaken to exploit the Finnish population structure to evaluate whether deletion mutations are recurrent or originate from common founders.

\section{Patients and methods PATIENTS}

This study is part of a nationwide multidimensional study of NPH in Finland. NPH is a progressive disease which always leads to renal failure with the eventual need for dialysis treatment and kidney transplantation. Conse- 


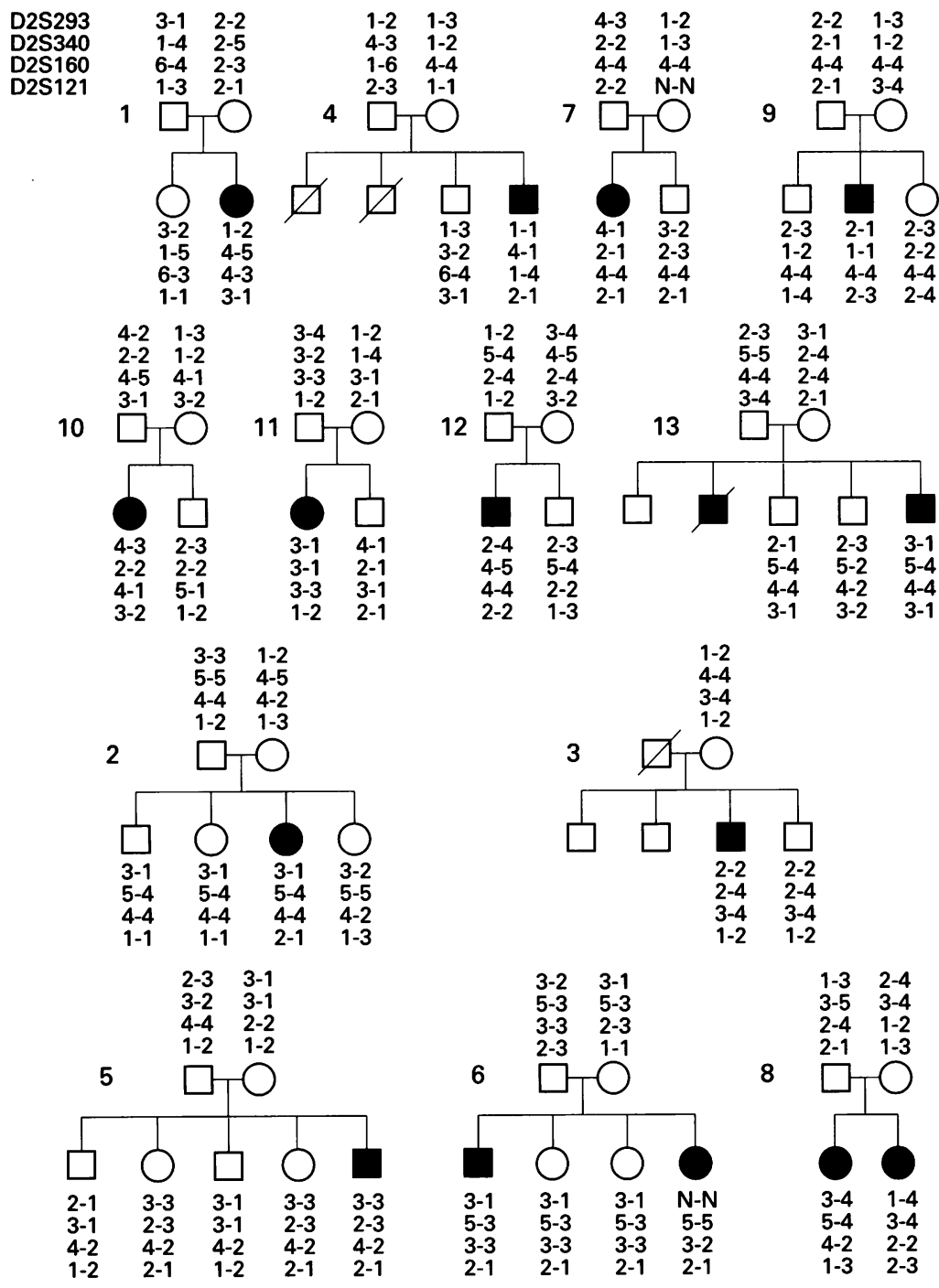

Figure 1 The pedigrees of families 1-13 and haplotypes for markers D2S293, D2S340, D2S160, and D2S121 corresponding to an interval of $6 c M(N=$ not determined).

quently, all the patients with NPH in Finland are treated and followed at five university hospitals and 16 central hospitals. All renal transplantations of both children and adults with NPH have been performed at the Helsinki University Hospital starting in 1964 and the Finnish Kidney Transplantation Register was founded at the same time. At the Children's Hospital of Helsinki University Hospital the register of patients younger than 16 years with chronic renal disease has been held since 1974 .

Three approaches were used to reach as complete an ascertainment of the patients as possible. (1) The files and hospital records of the Finnish Kidney Transplantation Register were evaluated from 1964 until the end of 1993 and comprised 2843 cases including both children and adults. (2) The nephrologists and paediatric nephrologists/paediatricians of all university and central hospitals were sent a questionnaire with a description of NPH in order to find patients at early stages. (3) The register of patients with chronic renal disease with and without renal insufficiency and kidney transplantation held from 1974 onwards was evaluated.

The primary search yielded 111 patients whose hospital records were collected and studied. The following selection criteria were used for inclusion in the study. (1) At least one of the following symptoms, polydipsia, polyuria, anaemia, or growth retardation, was considered obligatory. (2) Patients with urinary tract malformations, reflux, systemic diseases, or medication that might have caused chronic tubulointerstitial nephropathy were excluded. (3) The urinary findings had to show continuous inability to concentrate urine with decreased urinary specific gravity. No marked proteinuria or haematuria occurred. (4) The disease had to be progressive. (5) A renal biopsy of at least one affected subject in each family showing the characteristic tubulointerstitial nephritis of NPH, especially the thickened tubular basement membranes, was obligatory. (6) The patients should not have extrarenal manifestations. (7) Family members/sibs over 13 years without any clinical symptoms of NPH were considered as healthy and included in the study.

Altogether, we found 40 patients from 31 families who fulfilled the selection criteria. Blood samples for this study were collected from 72 members of 14 families: 19 patients and, whenever possible, their healthy sibs and parents. Four families had more than one affected subject while in 10 there was one affected subject with at least one healthy sib. In one of the multiplex families only the youngest of two brothers with NPH was alive.

In family 14 three sibships were closely interrelated. The family pedigrees are shown in figs 1 and 2 .

Genealogical studies were performed to determine the birth places of the parents and grandparents of the patients. The families were traced back four to six generations in search of common ancestors.

METHODS

\section{Detection of deletions}

DNA was extracted from $10-20 \mathrm{ml}$ of venous blood as described previously. ${ }^{18}$ All the patients, their healthy sibs, and parents were tested for the presence or absence of three non-polymorphic markers, 765F2L, 804/6, and $804 \mathrm{H} 10 \mathrm{R}$, which map to the $2 \mathrm{cM}$ interval between the flanking markers D2S1890 and D2S1888. ${ }^{17}$ Template DNA (45 $\mathrm{ng}$ ) was amplified in $25 \mu \mathrm{l}$ reactions in the presence of $10 \times$ PCR buffer, $0.5 \mathrm{mmol} / 1 \mathrm{dNTPs}, 12 \mathrm{pmol}$ of each primer, and $0.75 \mathrm{U}$ AmpliTaq DNA Polymerase $^{R}$ (Roche, Perkin Elmer). PCR reactions were carried out under conditions described for the polymorphic markers. An annealing temperature of $55^{\circ} \mathrm{C}$ was used for each reaction. The PCR products were electrophoresed on $2 \%$ agarose gels, ethidium bromide stained, and visualised under ultraviolet light.

\section{$P C R$ analysis of polymorphisms}

PCR conditions for the detection of polymorphisms were as follows: $30 \mathrm{ng}$ of template DNA, $5 \mathrm{pmol}$ of each primer, $0.2 \mathrm{mmol} / \mathrm{l}$ each of dATP, dGTP, and dTTP, $0.03 \mathrm{mmol} / 1$ dCTP, $700 \mathrm{nCi} \alpha{ }^{-32} \mathrm{P}$ dCTP, $0.3 \mathrm{U}$ of thermostable DNA polymerase (Dynazyme ${ }^{R}$, 


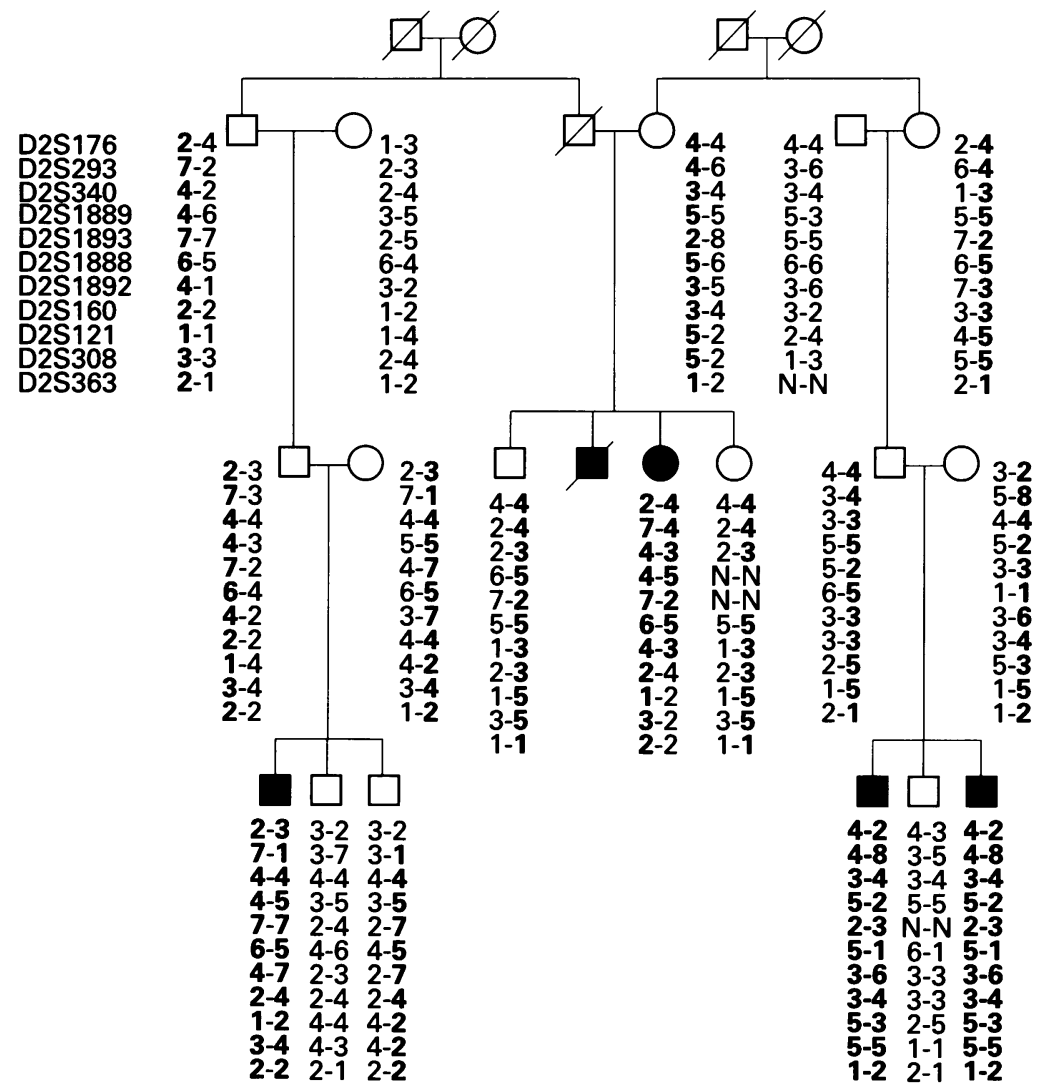

Figure 2 The pedigree of family 14 and the haplotypes for the markers studied ( $N=$ not determined).
Finnzymes), and $1 \mu$ of polymerase buffer recommended by the manufacturer. Following a denaturation step of $94^{\circ} \mathrm{C}$ for three minutes, the amplification was carried out during 30 cycles of denaturation $\left(94^{\circ} \mathrm{C}\right.$ for 45 seconds) and annealing $\left(55^{\circ} \mathrm{C}\right.$ for 45 seconds). An elongation step $\left(72^{\circ} \mathrm{C}\right.$ for four minutes) ended the process after the last annealing. Exceptionally, for D2S160 the annealing temperature was $64^{\circ} \mathrm{C}$, for $\mathrm{D} 2 \mathrm{~S} 1889$ it was $58^{\circ} \mathrm{C}$, and for $\mathrm{D} 2 \mathrm{~S} 1893$ it was $60^{\circ} \mathrm{C}$. After PCR, $10 \mu \mathrm{l}$ of loading buffer (formamide-bromophenol bluexylene cyanol 10:1) was added. After denaturation of the samples at $94^{\circ} \mathrm{C}$ for four minutes, 4 $\mu \mathrm{l}$ of the sample was electrophoresed on a $6 \%$ polyacrylamide $7 \mathrm{~mol} / 1$ urea sequencing gel. After electrophoresis the gels were dried and autoradiographed for six to 24 hours.

Linkage and haplotype analysis

A total of 14 families with NPH were typed with seven Généthon microsatellite markers, D2S135, D2S176, D2S293, D2S340, $\mathrm{D} 2 \mathrm{~S} 160, \mathrm{D} 2 \mathrm{~S} 121$, and D2S $308,{ }^{19}$ known to be linked to the NPH locus on chromosome $2 \mathrm{q}$ corresponding to an interval of about 15 cM..$^{1{ }^{15}{ }^{16}}$ In addition, family 14 was typed with polymorphic markers D2S1888 and D2S1892. For the haplotype analysis and allelic association studies, the patients and their parents and the members of family 14 were typed with two additional markers, D2S1889 and D2S1893, located within the $2 \mathrm{cM}$ critical interval. ${ }^{17} 20$ Complete penetrance of the disease allele and sex average recombination fractions were assumed. Linkage analyses were performed using the LINKAGE program package..$^{20}$ Pairwise lod scores were computed using the MLINK program.

Most likely haplotypes were constructed manually, assuming the minimum number of recombinations in each family.

\section{Results}

DETECTION OF DELETIONS

Fig 3 summarises the results of the deletion analysis with primers $765 \mathrm{~F} 2 \mathrm{~L}$ and $804 / 6$ and the haplotype and linkage analyses in all families. In families $1,4,7,9-14$ the amplified PCR products of primers $765 \mathrm{~F} 2 \mathrm{~L}$ and $804 / 6$ were not detected in the patients with homozygous deletions while the parents and healthy sibs showed the PCR products. In families $2,3,5$, 6 , and 8 the corresponding PCR products were detected in the patients as well as all the parents and healthy sibs. None of the patients, parents, or healthy sibs had absent PCR products with primer 80410R.

HAPLOTYPE ANALYSIS AND LINKAGE DISEQUILIBRIUM

Most likely haplotypes for the markers studied were constructed manually whenever possible by assuming the minimum number of recombinations. The results are shown in figs 1 and 2 . As families 1, 4, 7, 9-14 had apparently identical deletions, it was necessary to search for the possible existence of a founder effect behind this mutation. Evidence for a common ancestral disease associated haplotype was not

Figure 3 Summary of deletion, haplotype, and linkage data in 14 families with NPH. 
Table 1 Frequencies of the alleles on NPH1 chromosomes and normal chromosomes of parents with affected offspring with deletions

\begin{tabular}{|c|c|c|c|c|c|c|c|c|c|c|}
\hline \multirow[b]{2}{*}{ Marker } & & \multicolumn{8}{|c|}{ Alleles } & \multirow[b]{2}{*}{ Total } \\
\hline & & 1 & 2 & 3 & 4 & 5 & 6 & 7 & 8 & \\
\hline \multicolumn{11}{|l|}{ cen } \\
\hline \multirow[t]{2}{*}{ D2S340 } & NPH1 chromosomes & 4 & 3 & 1 & 7 & 3 & - & - & - & 18 \\
\hline & Normal chromosomes & 2 & 8 & 3 & 5 & 2 & - & - & - & 20 \\
\hline \multirow[t]{2}{*}{ D2S1889 } & NPH1 chromosomes & - & 4 & 1 & 3 & 12 & - & - & - & 20 \\
\hline & Normal chromosomes & 1 & 4 & 1 & 3 & 11 & 1 & - & - & 21 \\
\hline \multirow[t]{2}{*}{ D2S1893 } & NPH1 chromosomes & 一 & 9 & 5 & - & 2 & - & 4 & - & 20 \\
\hline & Normal chromosomes & 1 & 2 & 3 & 1 & 5 & 3 & 5 & 1 & 21 \\
\hline
\end{tabular}

Table 2 Added pairwise lod scores at different recombination fractions $(\theta)$ between the NPH1 gene and seven marker loci in NPH1 families with a deletion $(A)$ and without a deletion (B)

\begin{tabular}{lccccc}
\hline \multicolumn{7}{c}{$\theta$} \\
\cline { 2 - 5 } Locus & 0.00 & 0.01 & 0.05 & 0.1 & 0.2 \\
\cline { 2 - 5 } \multicolumn{7}{l}{ (A) Families with deletion } & $(1,4,7,9,10,11,12,13,14)$ & & \\
D2S135 & $-\infty$ & -0.67 & -0.03 & 0.20 & 0.23 \\
D2S176 & 1.55 & 1.17 & 1.01 & 0.84 & 0.49 \\
D2S293 & 3.89 & 3.80 & 3.35 & 2.81 & 1.83 \\
D2S340 & 1.39 & 1.37 & 1.19 & 0.98 & 0.54 \\
D2S160 & -1.05 & -0.04 & 0.44 & 0.49 & 0.41 \\
D2S121 & $-\infty$ & -0.78 & 0.41 & 0.76 & 0.67 \\
D2S308 & -1.78 & 0.31 & 0.85 & 0.95 & 0.80 \\
(B) Families without deletion & $(2,3,5,6,8)$ & & & \\
D2S135 & $-\infty$ & -2.97 & -1.56 & -0.97 & -0.43 \\
D2S176 & $-\infty$ & -2.36 & -1.47 & -0.98 & -0.46 \\
D2S293 & $-\infty$ & -4.79 & -2.53 & -1.56 & -0.64 \\
D2S340 & $-\infty$ & -4.13 & -1.99 & -1.14 & -0.41 \\
D2S160 & $-\infty$ & -2.77 & -1.38 & -0.83 & -0.34 \\
D2S121 & $-\infty$ & -1.69 & -0.73 & -0.33 & -0.06 \\
D2S308 & $-\infty$ & -4.56 & -2.37 & -1.45 & -0.62 \\
\hline
\end{tabular}

found. The allele frequencies on the NPH1 bearing chromosomes and normal chromosomes for markers D2S340, D2S1889, and $\mathrm{D} 2 \mathrm{~S} 1893$ are shown in table 1 . The distance between the flanking markers D2S1890 and $\mathrm{D} 2 \mathrm{~S} 1888$ is approximately $2 \mathrm{cM}$. The allele frequencies were evenly distributed on NPH1 bearing chromosomes and normal chromosomes. With marker D2S1889, 12 out of 20 NPH1 bearing chromosomes had allele 5 , but this was the most common allele in normal chromosomes too (11 out of 21), suggesting no linkage disequilibrium.

In families $2,3,5,6$, and 8 , no deletions were detected. In multiplex families 6 and 8, 2q13 was excluded as the site of the disease causing mutation by segregation analysis (fig 1). The two patients in family 8 had inherited different 2q13 haplotypes from their parents. In family 6 the older of the two patients had the same haplotypes as his two healthy sisters. The patients in these multiplex families reached end stage renal disease at the ages of $22,20,34$, and 24 years, respectively. In families 2,3 , and 5 , chromosome $2 \mathrm{q} 13$ was also excluded as the patients had inherited the same haplotypes as some of their healthy sibs. These patients reached end stage renal disease at the ages of 19,40 , and 26 years, respectively.

\section{LINKAGE RESULTS}

Results of pairwise linkage analyses with markers D2S135, D2S176, D2S293, D2S340, $\mathrm{D} 2 \mathrm{~S} 160, \mathrm{D} 2 \mathrm{~S} 121$, and D2S308 for all the families are shown in table 2 . Table 2 shows the combined lod score values after deletion analyses dividing the families into two groups: those having a deletion (A) and those having no deletion (B). The families having a deletion gave positive combined lod score values between 1.39 and 3.89 at a recombination fraction of 0 with markers D2S176, D2S293, and D2S340. A recombination in family 14 places the NPH1 locus proximal to D2S160 which is in accord with the results obtained by others. $^{14^{15} 17}$ Linkage to $2 \mathrm{q} 13$ could be excluded in families having no deletion by combined lod score values between -4.79 and -1.69 at a recombination fraction of 0.01 .

\section{GENEALOGICAL STUDIES}

Common ancestors for four patients were found, thus forming family 14 (fig 2), but not for the patients in families 1-13. The birth places of the parents and grandparents of the patients showed some accumulation in sparsely populated areas in western and central eastern parts of Finland. However, no definite regional clustering was seen (data not shown).

\section{Discussion}

The pathogenesis of NPH has remained unclear in spite of numerous research efforts studying the components of the thickened tubular basement membrane. Laminin and type IV collagen have been shown to have normal intensity and distribution by immunofluorescence with antibodies. ${ }^{7}$ Expression of the alpha 5 integrin fibronectin receptor has been found, suggesting altered cell substrate adhesion. ${ }^{8}$ Recent efforts have concentrated on attempts to isolate the NPH gene by positional cloning. Linkage analyses have localised the NPH1 gene to the interval between marker loci D2S293 and D2S121. ${ }^{15}{ }^{16}$ The interval, estimated to be approximately $2 \mathrm{cM}$, has been further refined by flanking markers D2S1888 and D2S1890 by haplotype analysis. The latest progress towards the isolation of the NPH1 gene has been the detection of homozygous deletions of $250 \mathrm{~kb}$ in the majority of the patients. ${ }^{17}$

The availability of nine Finnish families with 12 patients with NPH having a deletion in the chromosome $2 \mathrm{q} 13$ region and showing positive lod score values by linkage analysis provided an opportunity to search for a founder effect mechanism by linkage disequilibrium. The Finnish population is remarkably homogeneous owing to few founders and geographical isolation, which has led to a unique assortment of recessive disorders. ${ }^{22}$ Molecular genetic investigations of these diseases have shown that, in most cases, there is one major mutation enriched in Finland that accounts for each disorder. ${ }^{23}$ This is reflected by identical haplotypes in affected chromosomes of most patients, as in diastrophic dysplasia and infantile neuronal ceroid lipofuscinosis (INCL) ${ }^{24}{ }^{25}$ As no conserved haplotype was observed in NPH1 bearing chromosomes within the less than 2 cM critical region (table 1), a founder effect mechanism is very unlikely or even excluded in NPH1. Thus, the deletion hot spot theory suggested by Konrad et $a l^{17}$ is a more likely mechanism for NPH than a founder effect. 
$\mathrm{NPH}$ is genetically heterogeneous, ${ }^{15}{ }^{16}$ the NPH1 gene being responsible for approximately $85 \%$ of the purely renal form of NPH. A rearrangement of $2 \mathrm{q} 13$ has been detected in $80 \%$ of inbred or multiplex families and in $65 \%$ of families with sporadic patients. ${ }^{17}$ In these previously studied families showing linkage to $2 q 13$, the disease progressed to end stage renal disease before 21 years of age. ${ }^{15}$ In a considerable proportion of our families (five of 14), linkage to the NPH1 region could be excluded and no deletions were seen. This implies that in Finland substantially more than $15 \%$ of the pure renal form of NPH is not linked to the NPH1 region. Our patient series comes from a nationwide study with inclusion criteria similar to those applied in the linkage studies. ${ }^{13}{ }^{14}$ The reason for the larger proportion of families without the deletion could be the exceptional population history of Finland, reflecting a single NPH mutation elsewhere than in 2q13 and enriched in the Finnish population.

In the five families not linked to $2 \mathrm{q} 13$, end stage renal disease was reached and dialysis treatment began at the ages of $19,40,26,22$, 20,34 , and 24 (mean 32) years. Other clinical and pathological features of the patients did not differ from those who had deletions in whom end stage renal disease occurred between the ages of 8 and 16 (mean 12.4) years and in family 14 between 8 and 12 years. This suggests that NPH not linked to $2 \mathrm{q} 13$ is clinically different with slower progression. A more detailed analysis of the clinical features is in progress. Heterozygosity for the deletion could not be excluded in these families, but the results of the linkage analysis suggest that the NPH causing mutations are not located on chromosome $2 \mathrm{q} 13$ in these families.

We wish to thank Ms Sinikka Lindh for collecting blood samples and Professor Juhani Rapola who analysed the renal biopsies. This work was supported by grants from the Finnish Kidney Foundation and The Finnish Society of Nephrology.

1 Fanconi G, Hanhart E, Albertini A, Uhlinger E, Dolivo G, Prader A. Die familiäre juvenile nephronophthise. Helv Paediatr Acta 1951;6:1-49.

2 Smith CH, Graham JB. Congenital medullary cysts of the kidneys with severe refractory anemia. $A m \mathcal{F}$ Dis Child 1945;69:370-8.

3 Strauss MB. Clinical and pathological aspects of cystic disease of the renal medulla. An analysis of eighteen cases. Ann Intern Med 1962;57:373-81.
4 Strauss MB, Sommers SC. Medullary cystic disease and familial juvenile nephronophthisis. NEngl f Med 1967;277: 8amilial

5 Kleinknecht C, Habib R. Nephronophthisis. In: Cameron JC, Davison AM, Grunfeld JP, Kers KNS, Ritz E, eds. Textbook of clinical nephrology. Oxford: Oxford University Press, 1992:2188-97.

6 Waldherr R, Lennert T, Weber HP, Födisch HJ, Schärer K The nephronophthisis complex. Virchows Arch $(A)$ 1982; 394:235-54.

7 Cohen AH, Hoyer JR. Nephronophthisis. A primary tubular basement membrane defect. Lab Invest 1986;55:564-72.

8 Rahilly MA, Fleming S. Abnormal integrin receptor expression in two cases of familial nephronophthisis. Histopathology 1995;26:345-9.

9 Senior B, Friedmann AI, Braupo JL. Juvenile familial nephropathy with tapetoretinal degeneration. A new oculorenal dystrophy. Am $f$ Ophthalmol 1961;52:625-33.

10 Loken AC, Hanssen O, Halvorsen S, Jolster NJ. Hereditary renal dysplasia and blindness. Acta Paediatr Scand 1961;50: 177-84

11 Boichis H, Passwell J, David R, Miller H. Congenital hepatic fibrosis and nephronophthisis. $Q \mathcal{F}$ Med 1973;42:221-33.

12 Mainzer F, Saldino RM, Ozonoff MB, Minagi H. Familia nephropathy associated with retinitis pigmentosa, cerebellar ataxia and skeletal abnormalities. Am 7 Med 1970;49. 556-62.

13 Antignac C, Arduy CH, Beckmann JS, et al. A gene for familial juvenile nephronophthisis (recessive medullary cystic kidney disease) maps to chromosome 2p. Nat Genet 1993;3:342-5.

14 Hildebrandt F, Singh-Sawhney I, Schnieders B, et al. Mapping of a gene for familial juvenile nephronophthisis: refining the map and defining flanking markers on chromosome 2. Am f Hum Genet 1993;53:1256-61.

15 Medhioub M, Cherif D, Benessy F, et al. Refined mapping of a gene (NPH1) causing familial juvenile nephronophthisis and evidence of genetic heterogeneity. Genomics thisis and eviden

16 Hildebrandt F, Singh-Sawhney I, Schnieders B, Papenfuss $T$, Brandis $M$. Refined genetic mapping of a gene for familial juvenile nephronophthisis (NPH1) and physical mapping of linked markers. Genomics 1994;25:360-4.

17 Konrad M, Saunier S, Heidet L, et al. Large homozygous deletions of the $2 \mathrm{q} 13$ region are a major cause of juvenile nephronophthisis. Hum Mol Genet 1996;5:367-71.

18 Lahiri DK, Nurnberger JJ Jr. A rapid non-enzymatic method for the preparation of HMW DNA from blood for mFLP studies. Nucleic Acids Res 1991;19:5444.

19 Weissenbach J, Gyapay G, Dib C, et al. Second generation genetic linkage map of the human genome. Nature 1992;359:794-801.

20 Gyapay G, Morissette J, Vignal V, et al. The 1993-1994 Généthon human genetic linkage map. Nat Genet 1994;7: 246-339.

21 Lathrop GM, Lalouel JM, Julier C, Ott J. Strategies for multilocus linkage analysis in humans. Proc Natl Acad Sci USA 1984;81:3443-6.

22 Norio R, Nevanlinna HR, Perheentupa J. Hereditary diseases in Finland; rare flora in rare soil. Ann Clin Res diseases in Finlan

23 de la Chapelle A. Disease gene mapping in isolated human populations: the example of Finland. $\mathcal{F}$ Med Genet 1993;30: 857-65.

24 Hästbacka J, de la Chapelle A, Kaitila I, Sistonen P, Weaver $A$, Lander $\mathrm{E}$. Linkage disequilibrium mapping in isolated founder populations: diastrophic dysplasia in Finland. Nat Genet 1992;2:204-11.

25 Hellsten E, Vesa J, Speer MC, et al. Refined assignment of the infantile neuronal ceroid lipofuscinosis (INCL, CLN1) locus at 1p32: incorporation of linkage disequilibrium in multipoint analysis. Genomics 1993;16:720-5. 